\title{
Acute Gastroenteritis, Hepatitis, Pneumonitis, Myocarditis and Pericarditis after Pfizer-BioNTech COVID-19 Vaccine Injection in a Young Adult
}

\author{
Shoa-Lin Lin"* and Wei-Cheng Lin" \\ Division of Cardiology, Department of Internal Medicine, Kaohsiung Yuan's General Hospital, Kaohsiung City, Taiwan \\ \#These two authors contributed equally to this work
}

*Corresponding author: Shoa-Lin Lin, Division of Cardiology, Department of Internal Medicine, Yuan's General Hospital, 162, Cheng-Kung First Road, Lingya District, Kaohsiung 80249, Taiwan

\section{ARTICLE INFO}

Received: 㓞 November 10, 2021

Published: November 17, 2021

Citation: Shoa-Lin Lin, Wei-Cheng Lin. Acute Gastroenteritis, Hepatitis, Pneumonitis, Myocarditis and Pericarditis after Pfizer-BioNTech COVID-19 Vaccine Injection in a Young Adult. Biomed J Sci \& Tech Res 40(1)-2021. BJSTR. MS.ID.006394.

Keywords: Adverse Events; COVID-19 Vaccine; Gastroenteritis; Myocarditis; Pericarditis; Pneumonitis

\section{ABSTRACT}

COVID-19 is a disease caused by Severe Acute Respiratory Syndrome Coronavirus- 2 (SARS-CoV-2). The introduction of vaccines against COVID-19 caused great impacts in decreasing the severity of disease and in reducing further infection. However, COVID-19 vaccination related adverse events have caused a great concern in the public. We recently had an unusual case who presented with multi-organ involvement after Pfizer-BioNTech COVID-19 vaccination. The history was reported and the literatures were reviewed.

Abbreviations: SARS-CoV-2: Severe Acute Respiratory Syndrome Coronavirus-2; FDA: Food and Drug Administration; BNT: BioNTech COVID-19; DOE: Dyspnea on Exertion; PCT: Procalcitonin; CT: Computed Tomography; CV: Cardiovascular; CDC: Centers for Disease Control; MIS-C: Multisystem Inflammatory Syndrome in Children; ATAGI: Australian Technical Advisory Group on Immunization; CSANZ: Cardiac Society of Australia and New Zealand; CK: Creatine Kinase; GOT: Glutamic Oxaloacetic Transaminase; GPT: Glutamic Pyruvic Transaminase; ALP: Alkaline Phosphatase; Bil. (T), Bil.(D): Total Bilirubin Or Direct Bilirubin; CK: Creatine Phosphokinase; CK-MB: Creatine Phosphokinase-MB Isoenzyme; Pro-BNP: NT-Pro-BNP or N-Terminal Pro-Brain Natriuretic Peptide; CRP: C-Reactive Protein

\section{Introduction}

The two mRNA vaccines [Pfizer/BioNTech (BNT162b2) and Moderna (mRNA-1273)] demonstrated excellent safety and clinical efficacy profiles in clinical trials in adults. The United States Food and Drug Administration (FDA) has granted emergency authorization to the Pfizer/BioNTech (BNT162b2) and Moderna (mRNA-1273) COVID-19 vaccines on December 11, 2020 and December 18, 2020, respectively [1,2]. The commonly reported side effects of the vaccines included pain, redness and swelling at the administration site, malaise, headache, myalgias, chills, nausea, and fever. Myocarditis and/or pericarditis have been reported as rare side effects after mRNA COVID-19 vaccines (including Pfizer/ BioNTech and Moderna) in adults, particularly young adults
[3-5]. According to the best of our knowledge, the COVID-19 vaccination that involved multi-organs simultaneously (including acute gastroenteritis, hepatitis, pneumonitis, myocarditis and pericarditis) has not been reported previously. We hereby reported an interesting case with the above adverse events after PfizerBioNTech COVID-19 vaccination and review the relevant literatures.

\section{Case Report}

The patient was a 20 year-old healthy male with no previous medical history. He had received the first injection of PfizerBioNTech COVID-19 (BNT) vaccine on October 14, 2021. High fever $\left(39^{\circ} \mathrm{C}\right)$ developed in the evening after BNT vaccination. He received antipyretic drug which alleviated the fever temporarily. He then 
visited a local clinic and received antipyretic/analgesic medicines (Panadol 1tab PO TID) but the fever occurred intermittently. Due to persistent fever, cough, impaired appetite, and dyspnea on exertion (DOE), so he was brought to our emergency department for further evaluation and treatment on October 18, 2021. In the emergency department, a real-time reverse transcriptase-polymerase chain reaction (RT-PCR) test for COVID-19 was performed with a negative result. Other laboratory data showed increased C-reactive protein (CRP, 24.5mg/dL), hyperbilirubinemia [Bil(D)=1.16 mg/dL; $\operatorname{Bil}(\mathrm{T})=1.42(\mathrm{mg} / \mathrm{dL})]$, and abnormal liver function test [GOT=125 $\mathrm{U} / \mathrm{L}, \quad$ GPT(ALT) $=94 \mathrm{U} / \mathrm{L}]$. Patient was then admitted to the gastrointestinal (G-I) ward with preliminary impression of acute hepatitis on October $18^{\text {th }}$. At the G-I ward, infection was suspected due to high CRP and leukocytosis with left shift (WBC=12.1 $10^{\wedge} 3 /$ uL; Neutrophil=81.9\%). The Flumarin (Oxacephem) was used for board-spectrum coverage to treat the infection. In addition, patient had abnormal pro-BNP level (Pro-BNP $=1390.0 \mathrm{pg} / \mathrm{mL}$ ) and echocardiogram was studied, which revealed normal chamber size and left ventricular function (left ventricular ejection fraction, $\mathrm{LVEF}=67 \%$ ). No regional wall motion abnormality was found. On October $20^{\text {th }}$, patient again developed high fever $\left(39.3^{\circ} \mathrm{C}\right)$, right shoulder pain, epigastric pain, impaired appetite, and abdominal distention. Passage of loose stool and sometimes watery stool for more than 3 times daily was also noted.

The gastroenteritis was highly suspected. The Kascoal (Simethicone, 40mg) and Smecta (dioctahedral smectite, $3 \mathrm{~g}$ ) three times daily were prescribed. Meanwhile, the antibiotic was changed to ciprofloxacin for possible atypical infection. The passage of loose stool was persisted and Smecta was used until October $25^{\text {th }}$ when his discomfort was under controlled. Abdominal ultrasound revealed no obvious focal lesions. However, hypotension ( $\mathrm{BP}=81 / 52 \mathrm{mmHg}$ ) was noted on October $20^{\text {th }}$. After $500 \mathrm{cc}$ Lactated ringer infusion, the blood pressure increase to $101 / 66 \mathrm{mmHg}$. Unfortunately, hypotension $(81 / 49 \mathrm{mmHg})$ recurred in the evening of October $21^{\text {st }}$ even after $1000 \mathrm{cc}$ of the normal saline infusion. Chest X-ray showed cardiomegaly with bilateral pleural effusion and increased infiltration in both lower lungs, which suggesting the possibility of pneumonitis (Figure 1). Due to DOE, cardiomegaly with pleural effusion and elevated troponin I level (Troponin I=1590.0pg/ $\mathrm{mL}$ ), the acute myocarditis related to Pfizer-BNT vaccination was highly suspected. Thus, patient was transferred to ICU for further evaluation and treatment on October $22^{\text {nd }}$. In the ICU, due to suspected myocarditis, echocardiography was studied again on October 22nd, which revealed normal chamber size, small amount pericardial effusion, preserved LV systolic performance ( $\mathrm{LVEF}=62 \%$ ), and mild tricuspid regurgitation and mitral regurgitation. Since the pericardial effusion was not observed on the initial echocardiography performed 4 days ago, the new ECHO result indicated the newly developed pericarditis. Despite the use of antipyretic medication (Panadol 500mg TID), the patient had persistent fever (Figure 2), although the fever was trending down gradually. Since the procalcitonin (PCT) level was not high (PCT $=1.15 \mathrm{ng} / \mathrm{mL}$ ), the possibility of significant bacterial infection was excluded. Due to abdominal distention, dyspnea on exertion, and chest pain, we performed abdomen and chest computed tomography (CT) scans on October $22^{\text {nd }}$. These studies revealed

1) Air space infiltration in both lungs, consistent with pneumonia,

2) Subcutaneous edema of body wall of abdomen, suggesting of hypoalbuminemia,

3) Ascites and bilateral pleural effusions.

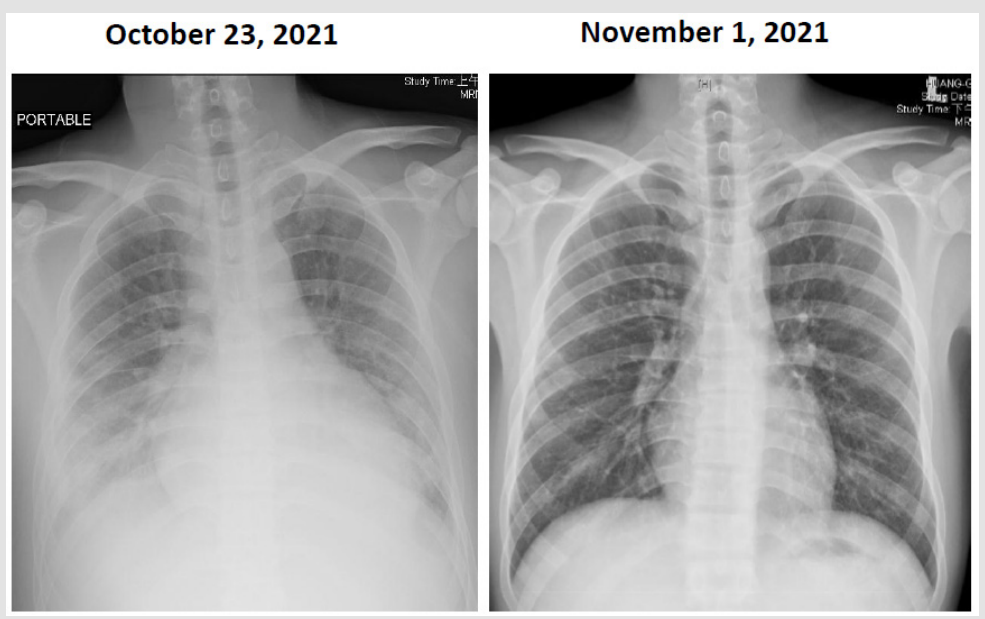

Figure 1:

Left: A chest film showing cardiomegaly with bilateral pleural effusion and increased infiltration in both lower lungs, which consistent with bilateral pneumonitis.

Right: Chest film examined after discharge, which demonstrates considerable improvement compared to that of the right-side chest film. 
A
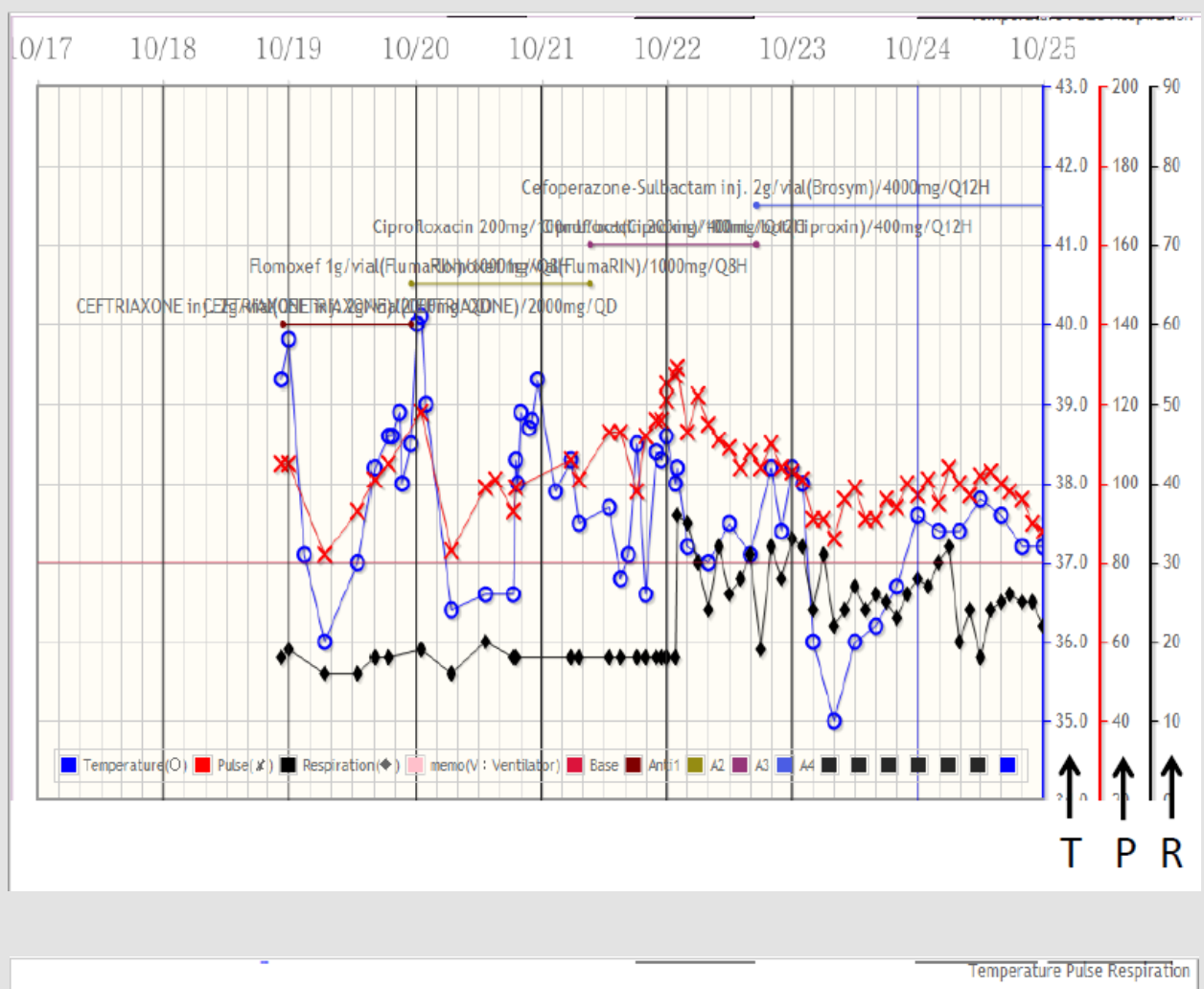

$\begin{array}{lllllll}0 / 25 & 10 / 26 & 10 / 27 & 10 / 28 & 10 / 29 & 10 / 30 & 10 / 31\end{array}$

B

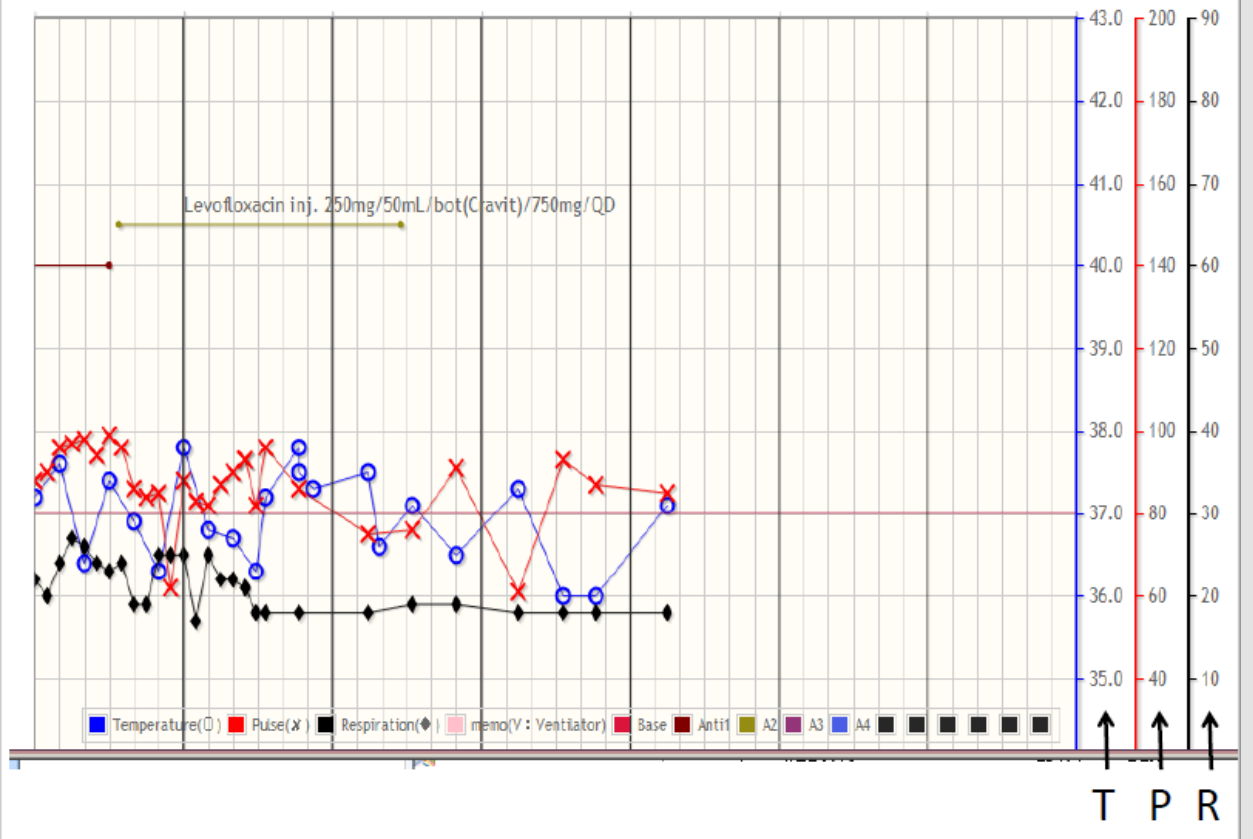

Figure 2:

Upper panel showing the curves of temperature, pulse rate, and respiratory rate, respectively from the 23:30 of October $18^{\text {th }}$ $(10 / 18)$ to the $0: 00$ of October $25^{\text {th }}(10 / 25)$. The blue circle, red cross, and black diamond represent the body temperature, pulse rate, and respiratory rate, respectively. The scales over the right side of the figures indicating those of the temperature (T), pulse rate $(\mathrm{P})$, and respiratory rate $(\mathrm{R})$, respectively. Please note, the high fever $\left(>39^{\circ} \mathrm{C}\right)$ exists during the initial 3 admission days.

Lower panel showing the curves of the temperature, pulse rate, and respiratory rate, respectively from 0:00 of October $25^{\text {th }}$ to 0:00 of November $1^{\text {st }}$. 
Due to hypoalbuminemia $(\mathrm{Alb}=2.72 \mathrm{~g} / \mathrm{dL})$, dyspnea on exertion, cough, ascites, and bilateral pleural effusion, Albumin $100 \mathrm{ml}$ and Lasix 20mg IV drip daily were used continuously for 6 days. Patient received vitamin D3 supplement treatment due to insufficient serum vitamin D level (Vitamin D, 25-OH-D=20.4ng/mL). The dosing schedule was 70,000 IU orally per day for 4 days, followed with 4000 IU daily until discharge. Lab data revealed that the Troponin I decreased from $1590.0 \mathrm{pg} / \mathrm{mL}$ to $61.7 \mathrm{pg} / \mathrm{mL}$; Pro-BNP dropped from $29069 \mathrm{pg} / \mathrm{mL}$ down to $1207 \mathrm{pg} / \mathrm{mL}$; CRP dropped from $24.5 \mathrm{mg} / \mathrm{dL}$ to $1.5 \mathrm{mg} / \mathrm{dL}$ after 7 days treatment.

His body temperature decreased gradually (ranged from $37.5^{\circ} \mathrm{C}$ to $37.8^{\circ} \mathrm{C}$ ) during October $24^{\text {th }}$ to $27^{\text {th }}$. Follow up echocardiography disclosed decrease in the amount of pericardial effusion on October $25^{\text {th }}$. On October $26^{\text {th }}$, the follow-up Lab data revealed considerable improvement (Table 1). Chest x-ray film also showed improvement of bilateral pleural effusion. After our aggressive treatments, his GI discomfort, chest pain, and shortness of breath improved gradually. Patient was transferred from the ICU to cardiovascular (CV) ward on October $26^{\text {th }}$ and discharged on October $28^{\text {th }}$. After discharge, he has visited our CV clinic on November $1^{\text {st }}$. The follow-up chest $\mathrm{x}$-ray film showed considerable improvement compared to previous chest x-ray film (Figure 1). There was no more cough or DOE. He received Kascoal (Simethicone) 40mg/tablet and Alginic acid (Algitab) $200 \mathrm{mg} / \mathrm{tab}$ for symptomatic treatment of the GI discomfort.

Table 1: Serial Biochemistry data.

\begin{tabular}{|c|c|c|c|c|c|c|c|c|c|c|}
\hline $\begin{array}{l}\text { Date/ } \\
\text { Time }\end{array}$ & $\begin{aligned} & \text { GOT }(\mathrm{U} / \mathrm{L}) \\
& \leqq 35\end{aligned}$ & $\begin{array}{c}\text { GPT (U/L) } \\
\quad \leqq 35\end{array}$ & $\begin{array}{c}\text { ALP (U/L) } \\
30-120\end{array}$ & $\begin{array}{c}\text { Bil.(T) } \\
\text { (mg/dL) } \\
0.3-1.2\end{array}$ & $\begin{array}{c}\text { Bil.(D) } \\
\text { (mg/dL) } \\
\leqq 0.20\end{array}$ & $\begin{array}{c}\mathrm{CK}(\mathrm{U} / \mathrm{L}) \\
\leqq 171\end{array}$ & $\begin{array}{c}\text { CK-MB } \\
\text { (ng/mL) } \\
\leqq 3.6\end{array}$ & $\begin{array}{l}\text { Troponin } \\
\text { I (pg/mL) } \\
\leqq 60.4\end{array}$ & $\begin{array}{c}\text { Pro-BNP } \\
\text { (pg/mL) } \\
\leqq 125\end{array}$ & $\begin{array}{c}\text { CRP (mg/ } \\
\text { dL) } \\
\leqq 0.3\end{array}$ \\
\hline Oct. 18 & 125 & 94 & & 1.42 & & & & 7.1 & & 24.5 \\
\hline Oct. 19 & & & 115 & & 1.16 & 66 & $<0.5$ & 12.2 & 1390 & \\
\hline Oct. 22 , am & 24.6 & 44 & 128.7 & 1.37 & 0.84 & 33 & 2.4 & 1590 & 29069 & 15.5 \\
\hline Oct. $22, \mathrm{pm}$ & & & & & & 22 & 0.8 & 808.9 & & \\
\hline Oct. 23 , am & & & & & & 14 & 0.7 & 821.7 & 24460 & 12.1 \\
\hline Oct. $23, \mathrm{pm}$ & & & & & & & & 553 & & \\
\hline Oct. 24 & & & & & & $<10$ & 0.5 & 254.5 & & \\
\hline Oct. 25 & 22 & 37 & 92 & 0.73 & 0.26 & $<10$ & $<0.5$ & 105.6 & 8342 & 4.2 \\
\hline Oct. 26 & & & & & & $<10$ & $<0.5$ & 61.7 & 4756 & 2.9 \\
\hline Oct. 28 & 18 & 33 & & & & & & & 1207 & 1.5 \\
\hline
\end{tabular}

\section{Discussion}

In the WHO's website, it seems that the reported side effects of COVID-19 vaccines have mostly been mild to moderate and have lasted no longer than a few days [6]. However, it was not the case for this patient. This patient developed persistent fever, cough, impaired appetite, and dyspnea on exertion after the first dose of Pfizer-BioNTech COVID-19 vaccine injection. The clinical and laboratory data subsequently showed the presence of acute gastroenteritis, hepatitis, pneumonitis, myocarditis and pericarditis. A recent article [7] has reported that the local and systemic reactions to mRNA-based COVID-19 vaccines occurred 0 to 7 days after vaccination, based on the Centers for Disease Control and Prevention (CDC) vaccine safe (v-safe) surveillance system. Data from millions of v-safe participants showed that the injection site pain and swelling were common for the local reactions after either of the mRNA-based vaccines (Pfizer and Moderna). As for the systemic reactions, more than $3 \%$ of the reported systemic symptoms included fatigue, headache, myalgia, chills, fever, joint pain, nausea, diarrhea, and abdominal pain. Although these reactions could occurred in participants after the first dose, they were more common after the second dose with either PfizerBioNTech or Moderna vaccine. These reactions were thought to be caused by the host's immune response. That article only described the local and systemic reactions within 7 days. In our report, the patient had high fever $\left(>39^{\circ} \mathrm{C}\right)$, measured by ear temperature, that persisted for 7 days (from October $14^{\text {th }}$ to $20^{\text {th }}$ ) after receiving the first dose of vaccine injection. The body temperature $>38{ }^{\circ} \mathrm{C}$ was noted for 3 days (from October $21^{\text {st }}$ to $23^{\text {rd }}$ ) and the temperature $>37.5{ }^{\circ} \mathrm{C}$ was noted for 4 more days (from October $24^{\text {th }}$ to $27^{\text {th }}$ ). Thus, the period of high fever days (7 days) and the total fever days (14 days) were unusual for this case.

Another point needed to be mentioned was that it usually takes a few weeks for the body to build immunity against SARS-CoV-2 virus after vaccination. Thus, it's possible that this individual could be infected with SARS-CoV-2 virus just before or after vaccination because the body did not have enough time to provide protection. Since this patient's RT-PCR test for COVID-19 was negative in the ED, the possibility of SARS-CoV-2 infection was unlikely. This case had evidence of myocarditis and pericarditis after Pfizer-BioNTech COVID-19 vaccination. It was consistent with previous report that 
there was absence of myocarditis and rare cases of pericarditis after receiving the non-mRNA COVID-19 vaccines (such as AstraZeneca vaccine or Johnson \& Johnson vaccine). However, cases of myocarditis and pericarditis in young men after mRNA vaccination were rising [8]. Several explanations have been hypothesized regarding why the myocarditis and pericarditis only occurred after the mRNA-based vaccines. First, a very strong antibody response was suspected to exist in a small proportion of the young adults that could produce a response similar to multisystem inflammatory syndrome in children (MIS-C) associated with the SARS-CoV-2 infection [9]. Second, the mRNA vaccines could induce a non-specific innate inflammatory response or a molecular mimicry mechanism between the viral spike protein and an unknown cardiac protein [10]. Molecular mimicry mechanism was caused by a significant similarity between certain pathogenic elements contained in the vaccine and the specific human proteins.

This similarity may lead to immune cross-reactivity, in which the reaction of the immune system towards the pathogenic antigens may harm human proteins that were similar in structures, essentially causing autoimmune diseases. Third, the mRNA, a potent immunogen, in the vaccine itself could trigger an adjuvant effect [11] by cytokine activation of the pre-existing autoreactive immune cells, which subsequently could induce autoimmune myocarditis. In August 2021, the Australian Technical Advisory Group on Immunization (ATAGI) and the Cardiac Society of Australia and New Zealand (CSANZ) have proposed a guidance in evaluating myocarditis and pericarditis after mRNA COVID-19 vaccination. This guidance suggested that findings consistent with myocarditis may include elevated troponin, ST or T-wave abnormalities observed on the ECG, premature atrial or ventricular complexes, and abnormal echocardiogram or cardiac MRI [12]. However, this guideline only suggested evaluating troponin but not the other cardiac enzymes such as creatine kinase (CK) or CK-MB isoenzyme. In our patient, it is interesting that the troponin I increased to a high level $(1590.0 \mathrm{pg} / \mathrm{mL})$ on October $22^{\text {nd }}$ and persisted for 4 more days (until October $25^{\text {th }}$ ). However, the other cardiac enzyme never elevated significantly during the whole course of hospitalization (Table 1). This specific phenomenon is worth to be mentioned.

Previous reports have found that vitamin D had immense benefits in the immune dysfunction observed in COVID-19 patients with cytokine storms [13-15]. It was also well known that vitamin D modulated the immune system by down-regulating the production of self-damaging pro-inflammatory cytokines and promoted the expression of anti-inflammatory cytokines by the immune cells [16-19]. Since the patient in this report had relatively low serum vitamin D level, he therefore received high dose vitamin D supplement treatment. The pneumonitis, myocarditis and pericarditis resolved smoothly after our treatment. Since vitamin D has immune-modulatory effects, we speculated that vitamin D may contribute to some extent to the recovery of this patient.

In conclusion, this report described an interesting case that had unusual presentations and with multi-organ involvements post Pfizer-BioNTech COVID-19 vaccination. After our aggressive treatment including vitamin D supplementation, he recovered completely without persistent symptoms.

\section{Authors' Contribution}

All authors have substantial contributions on the data collection, interpretation, and writing the manuscript.

\section{Declaration of Conflict of Interest}

The authors declare that there was no conflict of interest.

\section{Financial Support}

The authors declare that they have not received any financial support.

\section{References}

1. Polack FP, Thomas SJ, Kitchin N, Judith Absalon, Alejandra Gurtman, et al. (2020) Safety and efficacy of the BNT162b2 mRNA covid-19 vaccine. N Engl J Med 383(27): 2603-2615.

2. Baden LR, El Sahly HM, Essink B, Karen Kotloff, Sharon Frey, et al. (2021) Efficacy and safety of the mRNA-1273 SARS-CoV-2 vaccine. N Engl J Med 384(5): 403-416.

3. Kim HW, Jenista ER, Wendell DC, Clerio F Azevedo, Michael J Campbell, et al. (2021) Patients with acute myocarditis following mRNA COVID-19 vaccination. JAMA Cardiol 6(10): 1196-1201.

4. Abu Mouch S, Roguin A, Hellou E, Amorina Ishai, Uri Shoshan, et al. (2021) Myocarditis following COVID-19 mRNA vaccination. Vaccine 39(29): 3790-3793.

5. Larson KF, Ammirati E, Adler ED, Leslie T Cooper, Kimberly N Hong, et al. (2021) Myocarditis after BNT162b2 and mRNA-1273 Vaccination. Circulation 144(5): 506-508.

6. (2021) Side effects after COVID-19 Vaccine.

7. Chapin Bardales J, Gee J, Myers T (2021) Reactogenicity following receipt of mRNA-based COVID-19 vaccines. JAMA 325(21): 2201-2202.

8. Das BB, Moskowitz WB, Taylor MB, Palmer A (2021) Myocarditis and pericarditis following mRNA COVID-19 vaccination: what do we know so far? 8(7): 607 .

9. Grimaud M, Starck J, Levy M, Clémence Marais, Judith Chareyre, et al. (2020) Acute myocarditis and multisystem inflammatory emerging disease following SARS-CoV-2 infection in critically ill children. Ann Intensive Care 10: 69.

10. Segal Y, Shoenfeld Y (2018) Vaccine-induced autoimmunity: The role of molecular mimicry an immune cross-reaction. Cell Mol Immunol 15(6): 586-594.

11. Root Berstein R, Fairweather D (2015) Unresolved issues in theories of autoimmune disease varying myocarditis as a framework. J Theor Biol 375: 101-123.

12. (2021) Guidance on myocarditis and pericarditis after mRNA COVID-19 vaccines. 
13. Jain A, Chaurasia R, Sengar NS, Singh M, Mahor S, et al. (2020) Analysis of vitamin D level among asymptomatic and critically ill COVID-19 patients and its correlation with inflammatory markers. Sci Rep 10(1): 20191.

14. Huang C, Wang Y, Li X, Lili Ren, Jianping Zhao, et al. (2020) Clinical features of patients infected with 2019 novel coronavirus in Wuhan, China. Lancet 395(10223): 497-506.

15. Ye Q, Wang B, Mao J (2020) The pathogenesis and treatment of the "Cytokine Storm" in COVID-19. J Infect 80(6): 607-613.

16. Chambers ES, Hawrylowicz CM (2011) The impact of vitamin D on regulatory T cells. Curr Allergy Asthma Rep 11(1): 29-36.

\section{ISSN: 2574-1241}

DOI: 10.26717/BJSTR.2021.40.006394

Shoa-Lin Lin. Biomed J Sci \& Tech Res

(C) This work is licensed under Creative

Submission Link: https://biomedres.us/submit-manuscript.php
17. Adams JS, Hewison M (2008) Unexpected actions of vitamin D: New perspectives on the regulation of innate and adaptive immunity. Nat Clin Pract Endocrinol Metab 4(2): 80-90.

18. Lemire JM, Adams JS, Kermani Arab V, Bakke AC, Sakai R, et al. (1985) 1,25-Dihydroxyvitamin D3 suppresses human $\mathrm{T}$ helper/ inducer lymphocyte activity in vitro. J Immunol 134(5): 3032-3035.

19. Gombart AF, Pierre A, Maggini S (2020) A Review of micronutrients and the immune system-working in harmony to reduce the risk of infection. Nutrients 12(1): 236.

$\begin{array}{ll}\text { BIOMEDICAL } & \text { Assets of Publishing with us } \\ \text { RESEARCHES } & \text { - Global archiving of articles } \\ \text { - Immediate, unrestricted online access } & \text { - Rigorous Peer Review Process } \\ & \text { - Authors Retain Copyrights } \\ \end{array}$

